Carvalho, J.E.C. "Os grupos-nome: efeitos da substituição do imaginário pelo virtual na constituição dos grupos sociais"

\title{
OS GRUPOS-NOME: EFEITOS DA SUBSTITUIÇÃO DO IMAGINÁRIO PELO VIRTUAL NA CONSTITUIÇÃO DOS GRUPOS SOCIAIS
}

\author{
João Eduardo Coin de Carvalho \\ Universidade Paulista - UNIP
}

\begin{abstract}
RESUMO: Os grupos sociais categoriais são alvo, desde o pós-guerra, de uma intenso esforço de compreensão e demarcação conceitual, principalmente por parte dos psicólogos sociais europeus. A ampliação desta importância na pauta dos pesquisadores se deve ao aumento da presença relativa deste tipo de grupo no cenário das relações sociais e de suas conseqüências na produção das identidades sociais. Neste trabalho indicamos como o crescimento da importância dada aos grupos categoriais acompanha o esvaziamento progressivo do imaginário dos grupos, que passam a operar socialmente menos a partir das relações efetivas entre os indivíduos que os compõem e mais pela sua borda, isto é, o nome do grupo. Chamamos de grupos-nome a esses grupos virtualizados, que não têm presença material mas apenas imagética. Os grupos-nome tendem a ser mais freqüentes do que os grupos "vivos" na medida em que facilitam um relacionamento mais descompromissado entre os indivíduos e portanto mais confortável pela facilidade com a qual os indivíduos poderiam "trocar" de grupo social. Como efeitos da incidência dos grupos-nome destacam-se a transformação dos grupos face a face, a ampliação de mecanismos de controle e manipulação social e o incremento da violência.
\end{abstract}

PALAVRAS-CHAVE: identidade social, grupos, imaginário, virtual.

\section{NAME-GROUPS: THE SUBSTITUTION OF VIRTUAL FOR IMAGINARY IN SOCIAL GROUPS CONSTITUTION AND ITS EFFECTS}

ABSTRACT: Categorial social groups have been studied with more interest by the European social psychologists after Second World War. This research has been supported on the increase of this kind of group in the reality of social relations and in its effects on production of social identities. In this work we indicated how the importance of the categorial social groups goes along with the imaginary group fainting. Groups have 
Psicologia \& Sociedade; 14 (1): 28-43; jan./jun.2002

become outline presences than organizations based on relations. We nominated name-group these virtual groups, which doesn't have organic but only imagetic existence. Nowadays, name-groups are more common than "live" groups and this contributes to unreliable individual relationships and also makes possible people move to another group like changing clothes. Effects of name-group incidence are the least presence of "live" face to face groups, the ampliation of social control mechanisms and the growth in social violence.

KEY WORDS: social identity, groups, imaginary, virtual.

\section{INTRODUÇÃO}

A importância dada aos estudos sobre grupos categoriais, como nos trabalhos da Psicologia Social Européia, refere um fenômeno relativamente recente. No pós-guerra, TAJFEL, DOISE e MOSCOVICI, fundadores dessa tradição na psicologia social com trabalhos seminais, vão constituir um novo arcabouço teórico sobre os comportamentos coletivos. A relevância social atribuída por eles a estes comportamentos constituiu a oportunidade de buscar um entendimento para a pesquisa em psicologia social que visava tirá-la do "vácuo social" no qual estava mergulhada até então. A guerra, a possibilidade de extermínio de povos inteiros, o preconceito e a exclusão, assim como a oposição a um modelo hegemônico de se fazer ciência, estão na origem desta preocupação com as categorias sociais e sua dinâmica, o que irá produzir uma grande quantidade de trabalhos científicos na Europa, como "A representação social da psicanálise" (MOSCOVICI, 1984), caracterizando um novo paradigma para a psicologia social (FARR, 1999). Desde então, os grupos sociais categoriais, ou categorias sociais, vêm passando, tanto do ponto de vista do pesquisador na academia quanto do indivíduo no cotidiano, de fenômenos circunstancialmente importantes para presenças típicas das sociedades ocidentais contemporâneas.

Não que as categorias sociais não fossem relevantes antes disto. Sempre foi possível tratar de ingleses e americanos, negros e brancos, comunistas ou fascistas. Mas é a partir de meados da década de 50 que estes grupos "menos permanentes" passam a ter uma importância social mais evidente e efetiva, principalmente a partir do extraordinário desenvolvimento dos meios de comunicação de massa, da instituição de socie- 
Carvalho, J.E.C. "Os grupos-nome: efeitos da substituição do imaginário pelo virtual na constituição dos grupos sociais"

dades guiadas pela imagem - o cinema, a moda, a publicidade - e da disseminação destas imagens sociais como norteadoras de movimentos sociais para os quais faliram as explicações baseadas exclusivamente na razão (MORIN, 1984). Maio de 68, a Guerra Fria, os conflitos armados entre "subversivos" e "conservadores" nos países do 3o. mundo, fazem parte de um cenário no qual as categorias são imagens sociais que acompanham os indivíduos para além de seus vínculos orgânicos com qualquer um daqueles grupos. Uma determinada categoria social deixa de ser apenas uma referência distante para se caracterizar como um interlocutor importante no estabelecimento das nossas identidades. A identidade social entendida a partir dos vínculos dos indivíduos a grupos bem definidos e permanentes família, vizinhança, etnia, trabalho - passa então a ser constituída privilegiadamente pela associação com grupos sociais categoriais, menos constantes, mais claramente submetidos à ação do tempo, da história, das circunstâncias. A expansão da quantidade de referentes sociais produzida pela nossa sociedade como resultado da própria guerra, da expansão dos mercados via desenvolvimento econômico e da ampliação de um modelo hegemônico de sociedade guiado para o espetáculo e para o consumo, o que compreende os fenômenos de globalização econômica e mundialização da cultura (IANNI,1994), trazem como conseqüência o surgimento de cada vez mais novas categorias que têm o mesmo estatuto de "mercadorias sociais".

Ora, esse boom das categorias vem sendo acompanhado, no entanto, pelo que entendemos ser o esvaziamento do imaginário nesses grupos, que passam a ter, pela velocidade com que surgem e desaparecem, pela sua evanescência levada ao limite, uma existência concentrada nas suas bordas. A existência do grupo é apenas um contorno, uma imagem da qual o imaginário foi despregado, sobrando apenas seu traço. Esta imagem confere ao grupo a evanescência da mercadoria que não pode ser para sempre, ao mesmo tempo que conserva o grupo pela esvaziamento de sua porção plena de vida - o imaginário grupal (CARVALHO, 1999), desdobramento do imaginário radical proposto por CASTORIADIS (1995).

Para Castoriadis, desencantado com as explicações funcionalistas e estruturalistas dos fenômenos sociais, o imaginário radical é fruto da natureza e da história, fonte do que pode ser "materializado" em linguagem e imagem pelas sociedades humanas, e decisivo para compreender estes fenômenos. Em sua dimensão social, localizada historicamente, são produzidas e compartilhadas significações imaginárias sociais, que teriam uma contrapartida no âmbito mais específico dos grupos. Neste caso mais restrito é que poderíamos falar num imaginário grupal. Os elementos que o 
Psicologia \& Sociedade; 14 (1): 28-43; jan./jun.2002

compõem, decisivos na definição das identidades nos grupos, compreendem linguagem e imagens que circulam nos grupos e que juntas viriam constituir uma nova entidade, numa esfera onde o substrato seria o social. Assim, coexistiriam estes três universos, um linguageiro, outro imagético e de um terceiro que se apresenta no entrelaçamento dos dois primeiros, submetido à história, este o imaginário do grupo.

Entendemos que as sociedades contemporâneas estariam repletas de grupos sociais esvaziados deste imaginário grupal, grupos nos quais sua imagem estaria concentrada apenas num traço que é seu nome. É nesta passagem de grupo "vivo" para apenas grupo-nome, que o imaginário, morto, vai dar espaço à dimensão virtual do grupo.

\section{A ASSUNÇÃO DO VIRTUAL NO GRUPO: SUA MORTE SOCIAL}

A idéia de virtual aqui, tem um sentido bastante específico e é preciso não confundi-la com outros usos desta palavra já bastante estabelecidos e disseminados, assim como os juízos de valor que a acompanham. LÉVY (1996) e VIRILIO (1993, 1996a, 1996b) são dois dos pensadores contemporâneos que, em arenas opostas, melhor e mais intensamente têm tratado do que seja o virtual e de suas conseqüências. A discussão sobre o virtual como problematização (Lévy) ou como simulacro (Virilio), sobre a presença e as consequiências do virtual nas sociedades contemporâneas, nos interessam para que possamos situar sua inserção nos grupos. Privilegiando a perspectiva de Virilio sobre a desmaterialização trazida pelo virtual, concentramos nosso foco no efeito desta desmaterialização no grupo. Se o virtual vem ocupar o lugar do real na sociedade, substituindo-o, na nossa perspectiva é o "virtual" do grupo que se apresenta para tomar o lugar do imaginário grupal. Nesta passagem, porém, a desmaterialização seria melhor compreendida como desrealização do grupo. $O$ grupo se virtualiza quando perde sua vitalidade, quando o imaginário do grupo se esvai. No grupo sem imaginário, sem vida, sua presença vai estar concentrada naquilo que lhe sobra: sua imagem-nome. Desta forma, a vida do grupo, para todos os efeitos invisível porque instalada nos seus interstícios, vai ser substituída por uma imagem, cujo caráter "material" é que vai garantir a existência do grupo e sua interlocução social. $\mathrm{O}$ virtual oferece ao grupo algo que o imaginário não possui, uma consistência suportada pela imagem reificada do grupo, ainda que isto ofereça uma consistência supervolátil. A substituição do imaginário grupal pelo virtual não se dá como uma perda para o grupo, já que ele continua a "existir" através do virtual, a ter este 
Carvalho, J.E.C. "Os grupos-nome: efeitos da substituição do imaginário pelo virtual na constituição dos grupos sociais"

“corpo" que é a imagem do grupo. Se o imaginário para GUATTARI (1976), está presente naqueles elementos que alimentam a manutenção do grupo, para nós esta imagem que mantém o grupo materializado, será o virtual, aquilo que procura a manutenção do grupo, mesmo que através de sua morte.

O imaginário morre pela virtualização do grupo social. Nele, o virtual é a sobra, o resto da presença do imaginário. E ao mesmo tempo é a possibilidade do imaginário ser mais do que uma sombra, ser visível aos olhos, semelhante. O virtual é o imaginário feito corpo, isto é, o congelamento do imaginário, sua dimensão "morta" e materializada, como um retrato do grupo. Congelado, o imaginário, que agora é virtual, se oferece como uma referência muito mais efetiva nos jogos intergrupos e na sua assimilação imagética às identidades dos indivíduos. Se o virtual no grupo é índice da sua falência vital, ele também será a instituição aparente da sua permanência. No seu emparedamento, na construção de um mausoléu para o imaginário, o grupo persevera como numa escultura feita em pedra. Permanece sem existir.

\section{OS GRUPOS-NOME: PERMANÊNCIA E EXISTÊNCIA}

Chamo de grupos-nome aos grupos que são marcados por esta incidência do virtual; são os grupos cuja extração do imaginário constituiu sua presença social enquanto uma imagem estática, dando ao grupo virtualizado uma permanência aparente, já que mesmo "em pedra" um grupo não é perene. O nome do grupo condensa seu aspecto imagético, uma presença avassaladora que hoje assume o papel de mediador nos relacionamentos humanos. Estes grupos não têm a dimensão de algo que possa se conservar "vivo" pela sua importância social e são absolutamente voláteis. Vazios de imaginário, falta a eles a densidade que poderia garantir, ainda que provisoriamente, sua existência social. Esta existência é a identidade do grupo, e, qualquer que ele seja, a identidade está submetida à ação do tempo, está em movimento permanente, em metamorfose (CIAMPA, 1987), não é a mesma sempre, mas a mesma a cada instante $\mathrm{O}$ que oferece densidade ao grupo é seu imaginário, já que é através dele que o grupo garante uma identidade viva. Nos grupos-nome aquilo que se apresenta como sua identidade, e que portanto poderia "acumular" densidade, por assim dizer, é sua imagem. Mas essa imagem tem uma falsa inércia e não pode ter densidade para manter a vitalidade do grupo porque sua massa é falsa, é uma massa aparente. Mesmo que aparentando um objeto, uma coisa, o grupo- 
Psicologia \& Sociedade; 14 (1): 28-43; jan./jun.2002

nome não é mais do que um contorno vazado, apenas como uma imagem projetada na tela que é o social. Ele, o grupo-nome, não deixa de nos impressionar por conta disto. Como a imagem do cinema, ele pode ter movimento, pode parecer até tridimensional e cheio de vida. Mas, como é imagem, o grupo-nome apenas assombra, ele não existe. A imagem que não tem densidade para existir pode, no entanto, como imagem, permanecer enquanto durar a projeção.

É preciso considerar que assim como a identidade dos indivíduos, a de qualquer grupo social é suportada por uma falsa permanência. Todo e qualquer grupo parece ser "para sempre", sua identidade parece ser a mesma, permanente. Os grupos organizados, as instituições, têm nesta permanência sua força; criados para durar para sempre, sua existência é prevista para além dos indivíduos de carne, osso e desejo que as compõem, e através de estatutos, organogramas e objetivos declarados as instituições existem para permanecer. Já nas categorias sociais esta permanência é estabelecida histórica e socialmente. As mulheres, os homens ou mesmo os humanos, são categorias que têm suas presenças sociais garantidas menos por um suporte natural do que por sua condição historicamente construída. Seja como for, os relacionamentos entre os indivíduos reais que compõem qualquer grupo - uma categoria social ou uma instituição -, mesmo que pretendendo esta estabilidade, estão em permanente transformação. Para a pergunta sobre por que os indivíduos se organizam em grupos, as respostas possíveis parecem convergir na direção da sua permanência, dos indivíduos e dos grupos, permanência que eqüivale aqui à estabilidade e positividade destas instâncias, como descritas por TAJFEL (1982) ou, antes dele, por LEWIN (1965). Seja para manter-se fisicamente, na defesa contra inimigos ou predadores, na soma de esforços para superar uma dificuldade - o âmbito da necessidade - seja para a manutenção de uma identidade política, sexual ou moral, associada a um valor - o âmbito do desejo - a busca por permanecer, por não mudar, senão para uma lugar material ou socialmente mais positivo, é que parece agregar os indivíduos. Mas esta permanência no imaginário que é a vida do grupo, a permanência através de um líder ou a permanência na identidade que um nome pode oferecer, alinhadas numa mesma direção, se frustram pela descoberta de que nenhuma deles é perene, como aliás tudo o que é humano.

Mesmo considerando, com Guattari, que o imaginário do grupo está associado à sua manutenção, ele é também simultaneamente o antídoto contra esta permanência morta e a garantia, por outro lado, de sua existência social. Construído na história de relacionamentos de poucos ou de 
Carvalho, J.E.C. "Os grupos-nome: efeitos da substituição do imaginário pelo virtual na constituição dos grupos sociais"

um sem número de indivíduos, o imaginário do grupo seria assim melhor caracterizado como a antítese da permanência, já que é puro movimento porque é a vida do grupo, é o grupo. Assim, quando tratamos do virtual no grupo nos deparamos não apenas com uma tentativa de permanência, a qual é inerente a qualquer grupo social, mas com a busca da manutenção de sua existência através da simulação do imaginário no grupo, oferecendo, no entanto, uma falsa vitalidade ao que, sem imaginário, está morto. Desta forma, se enquanto grupo sua permanência já estava sob suspeita, como em todos os grupos, nos grupos-nome é a sua existência que fica agora comprometida.

Ancorada na materialidade de uma imagem, a existência do grupo-nome é falsa. Nos grupos-nome falta a vitalidade do grupo, isto é sua densidade imaginária, e essa existência é condição para uma "participação" efetiva no social. Enquanto os grupos vivos são aqueles que, reconhecidos socialmente, podem interferir no jogo que produz e mantém o imaginário social, grupos que têm uma participação de fato na dinâmica das sociedades, os grupos-nome são apenas marcas cuja participação não está na constituição do universo social, mas apenas na sua figuração. São os grupos que no cenário social funcionam como elementos que marcam a continuidade deste cenário. Não que eles não possam exercer efeitos sobre o imaginário social. Mesmo como apenas nomes, esses grupos produzem interferências. Um marcagrupo com estas características poderia ser, por exemplo, "as loiras" - um conjunto de mulheres de cabelo claro, sem qualquer relação necessária entre seus membros. Ainda que este grupo possa não comportar um imaginário, segundo o que entendemos como tal construído numa relação orgânica que possa ser associada a uma história comum daqueles indivíduos -, mesmo que ele seja apenas a borda a qual nos referíamos, a marca "loiras" não deixa de compor o cenário para a instalação dos outros grupos sociais. O nome "loiras" viria contribuir para a demarcação do grupo "mulheres", ou, em outras circunstâncias, para localizar no imaginário social o que seriam "top models" ou mesmo "artistas", por exemplo.

\section{O GRUPO-NOME COMO UMA CONDIÇÃO}

Os grupos-nome se caracterizam por esta sua oposição ao movimento. Os grupos plenos de imaginário estão submetidos às modulações sociais, ao movimento determinado pelos relacionamentos entre os indi- 
Psicologia \& Sociedade; 14 (1): 28-43; jan./jun.2002

víduos que compõem estes grupos. Sujeitos à história, às presenças dos outros grupos/categoriais sociais, os grupos vivos seguem o fluxo constante do social. Nos grupos-nome, por outro lado, a morte do grupo se dá pela oposição ao movimento. Mas não só. Ela também se dá pela presença enganadora de movimento, isto é, movimento aparente em direção a lugar nenhum. E é essa sensação de movimento que também colabora para inibir a transformação.

Tomemos, num outro exemplo, as organizações voltadas para a produção e para o lucro, que estariam, segundo nossa nomenclatura, virtualizadas. Nelas, depois de um longo tempo em que a "modernização" veio como sinônimo de movimento e atualização aparentes (CARVALHO, 1990), o índice mais evidente de paralisia passou a ser a busca por uma certa "qualidade total". Nestes casos, as supostas transformações sugeridas pelo uso dos nomes "empresa moderna", ou "empresa IS0 9000", são movimentos aparentes de um grupo morto, nos quais a organização e, mais especialmente a burocracia, contribuem para esvaziar o grupo de seus aspectos vitais.

De fato, a virtualização do grupo, sua transformação em gruponome, não é exclusividade dos grupos categoriais contemporâneos, grupos que seriam mais suscetíveis a esse esvaziamento, mas pode estar presente em qualquer grupo, mesmo que circunstancialmente. Os grupos organizados contemporâneos também se encontrariam nesta tendência à virtualização que alcança seu ápice com os grupos-nome. No grupo burocratizado a diferença entre os indivíduos está materializada e o controle sobre a morte do grupo se dá através da inércia infligida pela paralisia burocrática, a responsável pela inibição de qualquer tentativa de transformação (LAPASSADE, 1977). Isto não viria gerar, necessariamente, prejuízo ao imaginário do grupo. Mesmo submetido a um limitador - a burocracia da instituição - o imaginário do grupo pode continuar "agindo na escuridão", constituído nos relacionamentos profissionais ou não que ocorrem entre os membros desta instituição. Neste contexto, no entanto, os grupos burocraticamente organizados tendem a grupos-nome na medida em que mesmo estes grupos acabem por suprimir o imaginário do grupo através, por exemplo, da supressão dos relacionamentos entre os indivíduos em benefício dos relacionamentos entre funções (trabalho à distância, manutenção do grupo como uma máquina que pode ter as peças substituídas, etc.). Neste caso, são mantidas apenas as estruturas institucionais como suporte para o grupo, à imagem do esqueleto abandonado de um edifício 
Carvalho, J.E.C. "Os grupos-nome: efeitos da substituição do imaginário pelo virtual na constituição dos grupos sociais"

que já esteve em construção. Comparando estes grupos (burocraticamente) organizados com os grupos categoriais, se diria que nestes últimos não existe este esqueleto, mas apenas seu "desenho": ou tridimensional e povoado de imaginário ou bidimensional e vazio.

Além de poderem ser associados a grupos estruturados, abrindo o leque de possibilidades para sua presença social, os grupos-nome também devem ser considerados quanto a serem uma condição e, portanto, não se apresentarem assim permanentemente. Dizer que a "falta" de imaginário é uma condição procura dar conta da possibilidade de, num certo momento, um grupo-nome ver inflar sua dimensão imaginária que se ampliaria para aquém da borda do grupo, para dentro. Isto é, um nome, uma marca que apenas qualifica uma identidade, como uma placa informativa, pode vir a se constituir como uma referência orgânica - viva - a partir de seu reconhecimento social e de sua instalação não como apenas aquela placa mas como um teto que possa dar cobertura às imagens e linguagem de um conjunto de indivíduos que se identificam a este nome. Assim como qualquer grupo pode vir a ser circunstancialmente um grupo-nome, num momento do grupo em que a cobertura desaparece e só se vê a "placa", num outro momento o grupo pode voltar a ser "invadido" pelo imaginário grupal, um movimento que caracteriza justamente a evanescência e a vitalização dos grupos sociais. Isto é, o grupo pode vir a instituir, pela primeira vez ou novamente, uma história, relacionamentos orgânicos entre os indivíduos (objetivos, perspectivas, compartilhamento de um projeto/futuro comum) que, reconhecidos no social, conferem ao grupo a sua condição de vivo. Um exemplo: se num momento, os moradores de uma certa rua são apenas "vizinhos", um grupo-nome que não implica nenhuma outra relação orgânica, num outro momento esse mesmo grupo pode vir representar uma congregação com objetivos, comportamentos e possibilidades comuns que até há pouco podiam não existir e que fariam deste mesmo/novo grupo uma comunidade. É preciso indicar, ainda, que esta vitalidade do grupo baseada no imaginário não pode ser confundida com uma vitalidade biológi$c a$, como se o grupo fosse um ser vivo e o imaginário o que o preenchesse naturalmente. $\mathrm{O}$ imaginário se localiza no grupo como função de um movimento estritamente social, que o deposita nos grupos a partir de um reconhecimento, que é a entrada do grupo - linguagem e imagem - na arena em que se desenrola o social. Não vale a metáfora dos grupos vivos serem como seres vivos, mas sim como presenças sociais, e humanas, que se constituem histórica e contextualmente. 
Psicologia \& Sociedade; 14 (1): 28-43; jan./jun.2002

\section{A VIRTUALIZAÇÃO FAZ MESMO DOS PEQUENOS GRUPOS FACE A FACE SEMELHANTES AOS GRUPOS CATEGORIAIS}

Mesmo um grupo estruturado pode vir a ser virtualizado, e isto é verdadeiro inclusive entre os pequenos grupos nos quais os indivíduos se encontram (ou se encontrariam) numa unidade aparentemente "orgânica", como num grupo face a face, por exemplo. Na medida em que este processo de virtualização ganha força nas sociedades contemporâneas, traz como conseqüência um fenômeno bastante característico: a perda do caráter "grupal" nos grupos. O caráter "grupal" estaria na associação entre indivíduos que se reconhecem como fazendo parte de um mesmo time, isto é, indivíduos que tendo ou não uma função diferente no grupo, estão voltados para alcançar um certo objetivo. Num grupo face a face virtualizado, isto é, esvaziado de imaginário, o contorno do grupo que define sua permanência é o nome do grupo, sua imagem. Os relacionamentos entre os indivíduos, ainda que face a face, deixam de ser regulados mais especialmente pela presença de indivíduos de carne e osso que ocupam diferentes funções nesses grupos para se pautarem apenas pela referência à mesma marca comum, o mesmo nome que os congrega e que lhes confere uma identidade. Assim, pela virtualização, também os pequenos grupos perdem a especificidade do face a face, onde a mediação é realizada pela presença, digamos, "carnal", do outro, que é visto e ouvido como humano, por uma outra mediação na qual ele é apenas o outro, ou ainda, a imagem estrita que se faz deste outro.

Este componente, a imagem, está presente em qualquer relacionamento, e está lá também aonde não há ninguém senão sua presença em efígie, virtual. Nos relacionamos com pessoas sem as vermos - como pessoas. Não de hoje, é certo. Mas, atualmente, a frequiência destes contatos mediados é sensivelmente maior (THOMPSON, 1998). Além disso, a presença do outro parece não precisar ser sentida (ver e ouvir) mas apenas pressentida. Os outros são vistos como semelhantes através das imagens que nos são incessantemente repetidas - imagens dos grupos-nome que lhes são associados. Ouvimos e vemos não os outros propriamente, mas a mensagem de que há uma infinidade de outros que se parecem conosco, comem o que nós comemos, vestem o que vestimos, têm as mesmas doenças, os mesmos preconceitos. São tão parecidos conosco que não conseguimos enxergá-los nos nossos vizinhos. Este outro tão próximo, via imagem, é, no limite, apenas uma imagem.

Neste cenário de exclusão dos grupos vivos - e dos indivíduos 
Carvalho, J.E.C. "Os grupos-nome: efeitos da substituição do imaginário pelo virtual na constituição dos grupos sociais"

vivos - a perda do caráter "grupal" nos grupos valeria para todos eles: organizações, grupos categoriais ou pequenos grupos, todos são candidatos a grupos-nome. Nos grupos categoriais, quando as pessoas não estão face a face, o imaginário caracteriza e rege de maneira muito mais intensa e definidora o comportamento do grupo. Já nos pequenos grupos os indivíduos estariam sujeitos não apenas às injunções imaginárias, mas também às determinações transferenciais e relacionais do aqui-e-agora. Estão em jogo associações e oposições, atrações e repulsas, a relação com um líder, chefe, terapeuta, guru... Nos grupos face a face as relações seriam mediadas por objetivos comuns, pela presença de uma liderança - um representante ideal deste grupo - ou por um mediador - o terapeuta, por exemplo. A presença do outro, ainda que em efígie, por assim dizer, no pequeno grupo teria dimensão real, o outro estaria lá como presença que reage e co-determina os movimentos do grupo.

Mas apesar da possível presença de todos estes antídotos contra a virtualização, nos grupos que se caracterizariam pela relação face a face e pelo caráter supostamente pessoal - ou carnal - das relações entre os participantes, pelo encontro (ou confronto) entre eles, também estes elementos estão gradualmente desaparecendo graças às mesmas razões que determinam os grupos-nome: os indivíduos vão tendo também virtualizadas suas próprias presenças. A virtualização dos grupos tem como um de seus desdobramentos a promoção do desencontro e do isolamento entre os indivíduos, já que a identidade, a própria e a dos outros, fundada na associação a grupos sociais, vai constituindo como seu único suporte os nomes dos grupos ao invés do imaginário dos grupos. O outro, sua identidade, passa a ser compreendido na sua apresentação mais visível. As pessoas, as outras, perdem a consistência de um aglomerado imaginário, para se transformarem em apenas ícones, aglomerados, mas de nomes, que não são os nomes de família acompanhados de suas histórias. Perdem em profundidade e ganham em "colorido", como num caleidoscópio - daí pensar-se o crescimento da importância do vestuário ou do uso da pele, com as tatuagens e os piercings, enquanto apresentações desta casca identitária. Além disto, lidar apenas com esta aparência externa é mais estimulante e menos incômodo: afinal, é muito mais difícil tratar com pessoas que sejam, além de tudo, "essencialmente" diferentes. Os outros, identificados enquanto membros de grupos a partir de seus nomes/imagens, são, com maior intensidade, vistos menos como pessoas e mais como estes representantes plenamente convertidos em imagem, desde que os nome dos grupos a que estão 
relacionados não tem dimensão imaginária, mas apenas imagética.

Desta forma, aquilo que faria a diferença entre o pequeno grupo e os grupos sociais, a presença "real" na relação, tem sua dimensão reduzida na medida em que as identidades tendem a se constituir como absolutas "sou um ser único" - e tipificadas - quando os indivíduos se apresentam como modelos de um tipo de identidade, que pode ser trocada em função das circunstâncias e de quem são os outros indivíduos. Como consequiência, no pequeno grupo as relações entre os indivíduos também vão perdendo materialidade, vão se virtualizando, da mesma forma que nos grupos categoriais, com os indivíduos associando uns aos outros identidades estereotipadas, ao invés de enfrentar os conflitos inerentes às relações $v i$ vas, com suas mudanças e vissicitudes, solicitando deles uma permanente disposição para sua ressignificação (redescrição). Estas relações virtuais, comportando menos conflito porque sem vida, vão ampliar sua presença na medida em que são criados "facilitadores" para a virtualização, como a explosão dos meio de comunicação de massa, difundindo os modelos sociais hegemônicos das sociedades de consumo, e o desenvolvimento das tecnologias de comunicação, como a Internet, proporcionando uma maior freqüência de contatos virtuais entre os indivíduos.

\section{CONCLUINDO: CONTROLE SOCIAL E VIOLÊNCIA}

Uma das decorrências desta incidência dos grupos-nome pode ser aferida nos instrumentos de controle social. Na medida em que os pequenos grupos se assemelham aos grupos categoriais esvaziados de imaginário, as possibilidades de manipulação nos primeiros se tornam mais evidentes, já que não é preciso lidar com os aspectos imaginários e relacionais na dinâmica dos grupos, bastando intervir sobre sua borda. Os efeitos disto nas organizações são devastadores. Não parece mais fácil intervir sobre um grupo de funcionários mais identificados a uma marca (o nome da empresa, o departamento) do que tendo relacionamentos típicos dos grupos orgânicos face a face? Qual o poder de controle e manipulação que pode ser exercido por chefes e gerentes sobre suas "equipes" esvaziadas de imaginário? A importância desse assemelhamento tem conotações claramente ideológicas: tudo que incentive o surgimento e a manutenção destes grupos voláteis em detrimento dos grupos "reais" solidários - como por exemplo, comunidades, grupos políticos, grupos profissionais - ofereceria condições para um maior efeito das manipulações para o controle ou 
Carvalho, J.E.C. "Os grupos-nome: efeitos da substituição do imaginário pelo virtual na constituição dos grupos sociais"

para a indução de comportamento, como o obtido através da publicidade, mantendo a hegemonia de uns grupos sobre outros (THOMPSON, 1995). Estes indivíduos que se vêem pertencendo privilegiadamente a grupos-nome, engajados em relacionamentos virtuais, seriam muito mais suscetíveis de serem convencidos pelo poder da imagem. Por outro lado, a sobra do imaginário que continua presente dentro das instituições - afinal, os indivíduos dentro delas continuam em alguma medida se relacionando -, alimenta um velho vilão: neste cenário virtualizado ela pode ser deslocada com mais intensidade do papel de sintoma institucional para o de sintoma nos indivíduos, caracterizando-os como supostamente incapazes de se relacionar de "maneira profissional", já que nem sempre conseguem manter a frieza dos relacionamentos nas bordas das instituições e, inevitavelmente, sofrem, o que valoriza todas as abordagens institucionais que privilegiam nela a presença do imaginário, em oposição à instituição como espaço físico - e virtual (GUIRADO, 1987)

Também em relação ao incremento da violência os grupos-nome estariam relacionados. Um conjunto de pessoas que compartilhe uma mesma identidade constitui um grupo social. Ele pode ser um grupo vivo e compartilhar imagens e discursos comuns ou ser um grupo-nome. Nos grupos-nome o compartilhamento da imagem que sustenta o grupo e que carrega sua identidade traz consigo uma pauta de comportamentos e de disposições que estão "coladas" ao nome, estereótipos que ajudam a delinear sua imagem. Esse compartilhamento não se dá pelo encontro, mas por contaminação. Neste caso as pautas são compartilhadas porque isto corresponde a fazer parte do grupo. Num exemplo, se o preconceito em relação aos homossexuais por um grupo de carecas neonazistas brasileiros pode indicar um compromisso político ou teórico, por outro lado pode apenas sustentar o vínculo à imagem daquele grupo, e isto enquanto durar seu relacionamento com esta imagem. Da mesma forma, a aversão à ordem e às instituições da sociedade geralmente associada aos jovens punks, por exemplo, é como um "adereço" que o indivíduo toma ao se considerar parte daquele grupo. Infelizmente, esta fragilidade do vínculo ao grupo não implica comportamentos menos efetivos por parte dos membros destes grupos: um jovem neonazista pode, por exemplo, e apesar da fragilidade de sua identidade, ser extremamente violento com este outro homossexual. O notável neste caso é que a inconsistência da identidade pode levar à instabilidade no comportamento: mudando de grupo, o indivíduo muda de comportamento como quem muda de roupa. Um adolescente de classe média "sem antecedentes" e bem comportado poder se transformar de um mo- 
Psicologia \& Sociedade; 14 (1): 28-43; jan./jun.2002

mento para outro num perigoso piromaníaco, ou no assassino de colegas de classe, o mesmo que acontece entre adultos exemplares que atiram uns nos outros por um desentendimento no trânsito ou numa reunião de condomínio.

Contemporaneamente, assim, se verificaria a instabilidade e a efetividade de um caráter da identidade que, via de regra, não pode mais ser atribuído apenas a uma traço da adolescência, período de grandes e profundas transformações em que se tolera esta instabilidade. Em nossas sociedades, cada vez mais, a imensa maioria dos relacionamentos sociais vêm se fazendo neste vazio imaginário, com importantes conseqüências para a manutenção do controle social e para a disseminação epidêmica da violência.

\section{REFERÊNCIAS BIBLIOGRÁFICAS}

CARVALHO, J.E.C. Grupos-Nome e Identidades Adolescentes: Uma Proposta de Entendimento para a Virtualização do Cotidiano. Tese de Doutorado apresentada ao Instituto de Psicologia da Universidade de São Paulo, 1999.

CARVALHO, J.E.C. Transferência de Tecnologia no Setor de Cerâmica Vermelha: as Representações Sociais do Moderno e da Modernização. XX Reunião da Sociedade de Psicologia de Ribeirão Preto, 1990.

CASTORIADIS, C. A Instituição Imaginária da Sociedade. 3a. edição. Rio: Paz e Terra, 1995.

CIAMPA, A. C. A história de Severino e a estória de Severina. São Paulo: Brasiliense, 1987.

FARR, R. Raízes da Psicologia Social Moderna. Petrópolis: Vozes, 1999

GUATTARI, F. Psicoanalisis y Transversalidad. Buenos Aires: Siglo XXI, 1976.

GUIRADO, M. Psicologia institucional. São Paulo: EPU, 1987.

IANNI, O. Globalização: Novo Paradigma das Ciências Sociais. Estudos Avançados 8(21): 147-163, 1994 
Carvalho, J.E.C. "Os grupos-nome: efeitos da substituição do imaginário pelo virtual na constituição dos grupos sociais"

LAPASSADE, G. Grupos, organizações e instituições. Rio de Janeiro, Francisco Alves, 1977

LÉVY, P. O que é o Virtual? Rio de Janeiro: Editora 34, 1996.

LEWIN, K. Teoria de campo em ciência social. Rio de Janeiro: Pioneira, 1965.

MORIN, E. Cultura de Massas no Século XX: o Espírito do Tempo - voll: Neurose. Rio de Janeiro: Forense-Universitária, 1984.

MOSCOVICI, S. A representação social da psicanálise. Rio: Zahar, 1984

TAJFEL, H. Grupos Humanos e Categorias Sociais. Lisboa: Horizonte, 1982

THOMPSON, J. B. Ideologia e cultura moderna: teoria social crítica na era dos meios de comunicação de massa. Petrópolis: Vozes, 1995.

THOMPSON, J.B. A mídia e a modernidade: uma teoria social da mídia. Petrópolis: Vozes, 1998.

VIRILIO, P. A Arte do Motor. São Paulo: Estação Liberdade, 1996a

VIRILIO, P. Cybermonde: la Politique du Pire. Paris: Textuel, $1996 \mathrm{~b}$.

VIRILIO, P.O Espaço Crítico. Rio de Janeiro: Editora 34, 1993. 
Psicologia \& Sociedade; 14 (1): 28-43; jan./jun.2002

João Eduardo Coin de Carvalho

E-mail: joaocoin@yahoo.com

Doutor em Psicologia pela Universidade de São Paulo

Responsável pela Cadeira de Psicologia Social do

Curso de Psicologia da Universidade Paulista (UNIP)

Coordenador do CEPPE - Centro de Estudos e

Pesquisas em Psicologia da UNIP

Instituição em que trabalha atualmente:

Universidade Paulista - UNIP (SP)

João Eduardo Coin de Carvalho

Os grupo-nome: os efeitos da substituição do imaginário pelo virtual na constituição dos grupos sociais.

Recebido dia: 15/5/2002

$1^{\text {a }}$ revisão: $26 / 7 / 2002$

Aceite final: 7/8/2002 